\title{
Implementação do Programa Saúde na Escola no Colégio Municipal Pedro Amado - Petrópolis/RJ: um relato de experiência interdisciplinar
}

\author{
Rafaella Araújo de Azevedo, Mariana Leal Marcolino, Desirré Mathias, Raphael Curioni
}

\begin{abstract}
Resumo
O Programa Saúde na Escola (PSE) resulta do trabalho integrado entre o Ministério da Saúde e o Ministério da Educação, na perspectiva de ampliar as ações específicas de saúde aos alunos da rede pública de ensino, com a finalidade de contribuir para a formação integral dos estudantes por meio de ações de prevenção, promoção e atenção à saúde. Dessa forma, unem-se os setores saúde e educação, buscando o trabalho conjunto entre a equipe do Programa Saúde da Família e a equipe pedagógica da Escola. Relatar a experiência da equipe do PSF - Meio da Serra no Colégio Municipal Pedro Amado, ambos localizados no município de Petrópolis, com inicio em Junho de 2016, e ainda em andamento. O Programa deu-se inicio com a pactuação deste entre a equipe do PSF e a equipe pedagógica do Colégio, realizando-se o levantamento das necessidades e demandas. Em seguida, fez-se o planejamento da ação, definição do calendário das atividades, discussão dos temas que serão abordados e construção dos materiais que serão utilizados. Também foi realizada a apresentação do Programa para as famílias dos alunos e para a equipe pedagógica da escola. Os temas trabalhados foram: Higiene Corporal; Higiene Bucal; Promoção das práticas corporais e atividade física nas escolas; Promoção da cultura de paz e prevenção das violências; Ações de segurança alimentar e promoção da alimentação saudável; Educação para a saúde sexual, saúde reprodutiva e prevenção das DST/aids; Prevenção ao uso de álcool e tabaco e outras drogas; Promoção da saúde ambiental e desenvolvimento sustentável. Todas as temáticas foram tratadas de acordo com cada faixa etária, respeitando-se o nível de cognição, a linguagem e as particularidades sócio-culturais de cada grupo. As intervenções foram realizadas em conjunto pelos profissionais da UBS - Meio da Serra, (Residentes em Psicologia e Enfermagem, Enfermeira, Cirurgiã-Dentista, Técnica em Saúde Bucal, Técnica em Enfermagem, e Agentes Comunitárias de Saúde), com a participação dos docentes e discentes do Colégio, e com o apoio da Secretaria de Saúde de Petrópolis. Participaram ao todo cerca de 234 alunos, divididos em 10 turmas, que contemplam o $1^{\circ}$ seguimento (Ensino Infantil ao $5^{\circ}$ ano $)$ e o $2^{\circ}$ seguimento $\left(6^{\circ}\right.$ ao $8^{\circ}$ ano). Tem-se que o trabalho realizado, apesar de ainda não finalizado, uma vez que se busca a sua longitudinalidade, mostrou-se bem sucedido, visto que possibilitou a discussão de temáticas da saúde numa perspectiva ampla, de forma lúdica, horizontal e participativa. O PSE é um Programa que busca proporcionar aos jovens experiências de contato com temáticas poucas vezes trabalhadas em sala de aula, de forma lúdica, participativa, horizontalizada e integrativa. Assim, almeja-se uma aproximação da saúde na perspectiva da prevenção de doenças e agravos, e na promoção do bem-estar individual e comunitário e na qualidade de vida.
\end{abstract}

Descritores: Programa Saúde na Escola; Atenção Básica; Interdisciplinaridade. 